\title{
Herpes Simplex Virus Infections of the Nipple
}

\author{
Lara El Hayderi, Marie Caucanas and Arjen F. Nikkels
}

Department of Dermatology, University Hospital of Liège, Liège, Belgium

\begin{abstract}
The usual sites of herpes simplex virus (HSV) type 1 and 2 infections are orolabial and anogenital, respectively. HSV infection of the nipple and periareolar area is exceptional but probably underrecognized. Typical features include severe pain and erosive or ulcerated erythematous confluent clusters of lesions of the nipple and periareolar area. It is usually unilateral and not recurring. HSV infection of the nipple is originating from autoinoculation, sexual transmission or breastfeeding. Diagnosis is often delayed. The Tzanck smear is the most rapid and adequate method of diagnosis. Immunohistochemistry enables viral identification. The treatment relies on topical disinfection and oral antiviral therapy, such as aciclovir, famciclovir or valaciclovir. Scarring is uncommon.
\end{abstract}

Keywords: Herpes simplex virus, nipple, areola, aciclovir.

\section{INTRODUCTION}

Herpes simplex virus (HSV) type-I and -II are responsible for orolabial and anogenital herpes, respectively. HSV-I or -II infections of the pubis, the bursa, the finger or the hair follicle are more seldom [1-5]. HSV infections of the nipple and/or areola are rather exceptional.

Three patients are presented with HSV infection of the nipple, as well as a literature review.

\section{CASE REPORTS}

1. A 20-year-old woman presented at the emergency ward for a painful ulcerated lesion of her left nipple. There was no particular medical or surgical history other than a mild atopic dermatitis. She did not take any drugs. The lesion, affecting the entire areola and nipple (Fig. 1), was erythematous, ulcerated and extremely painful. She applied a zinc paste to alleviate the erosions. A left axillar lymphadenopathy was palpated. She presented no fever. A Tzanck smear was performed to exclude a viral infection. The immunohistochemical identification [6,7] was positive for HSV-1, whereas the HSV-2 and varicella zoster virus (VZV) stainings were negative. Serology showed a past HSV infection (IgG: +, IgM: -). The patient was not breastfeeding but had oral/handnipple contact with her partner who regularly experienced recurrent orolabial herpes (RHL). The patient and her partner did not suffer from genital herpes. Oral aciclovir $(5 \times 200 \mathrm{mg} / \mathrm{d})$ was initiated for 7 days and about 10 days later, there was a complete resolution with no residual scarring. She never presented any recurrent herpetic lesion at this site until today.

*Address correspondence to this author at the Department of Dermatology, CHU of Sart Tilman, University of Liège, B-4000 Liège, Belgium;

Tel: +32-43667232; Fax: +32-43667234; E-mail: af.nikkels@chu.ulg.ac.be

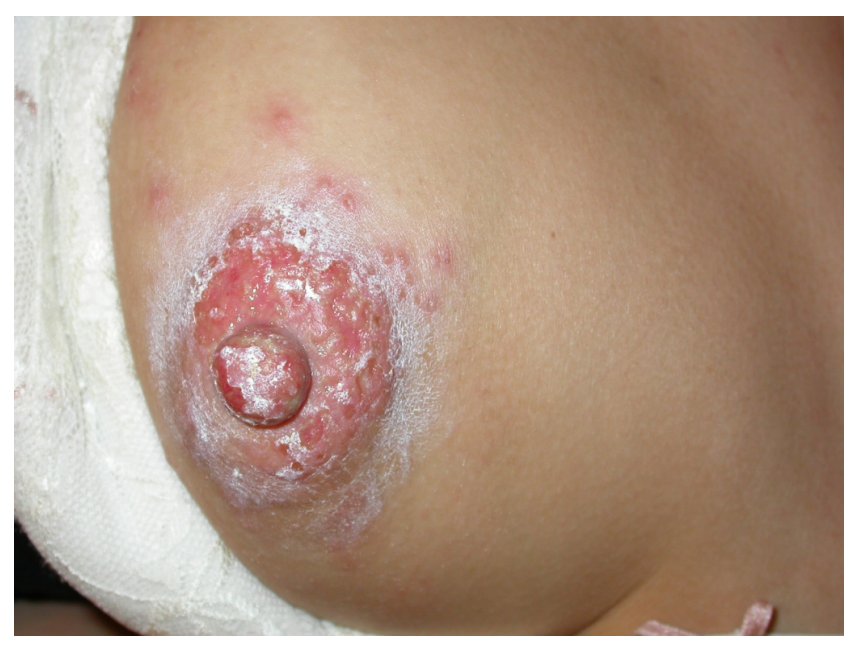

Fig. (1). Erythematous and infiltrated HSV-1 infection of the nipple and areola.

2. A 38-year-old woman was admitted at the emergency ward for very painful, eroded and soothing lesions of her left nipple. She never presented similar lesions previously. She was otherwise healthy and did not take any medication. She was non-lactating. Her partner presented RHL and the lesions presented 2 days after oral contact with the nipple. The breast was not swollen or painful and there was a unilateral axillar lymphadenopathy. The patient and her partner were not afflicted by genital herpes. Immunohistochemistry applied to a Tzanck smear revealed a positive signal for HSV-2 antigens (Fig. 2), but no signal for HSV-1 or VZV antigens. A treatment with oral aciclovir $(200 \mathrm{mg}, 5 \mathrm{x} / \mathrm{d})$ was given for 10 days. A topical disinfection treatment was applied. After two weeks, no residual lesions were noted and the pain had disappeared completely. 


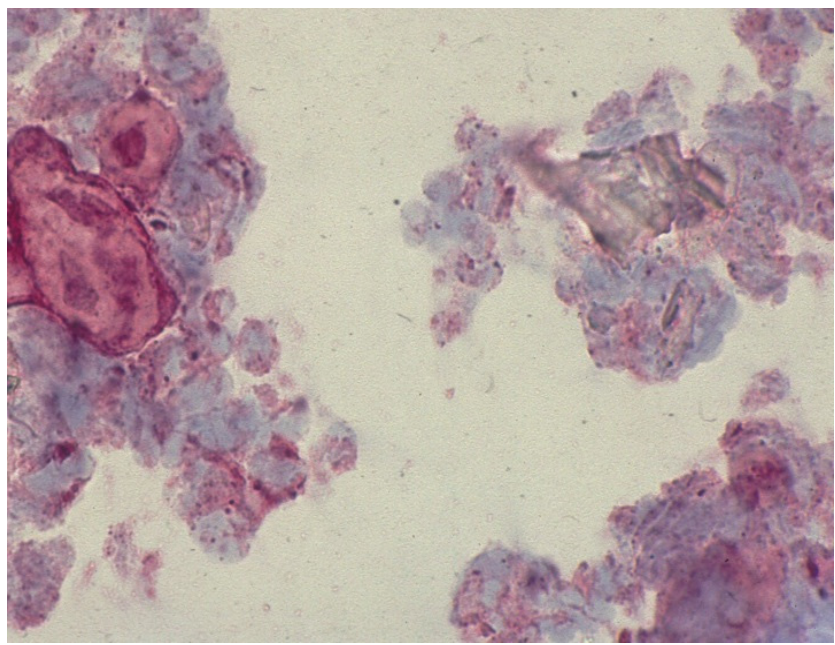

Fig. (2). HSV-2 positive immunostaining in multinucleated keratinocytes (Tzanck smear, Red signal, 100x).

3. A 48-year-old woman without any remarkable medical history presented a painful, soothing and eroded dermatosis on the right nipple and superior part of the areola. Bisoprolol was the only medication. This lesion appeared after a slightly traumatic oral/genital-nipple contact with her partner, who suffered from recurrent genital herpes. She presented a right axillar lymphadenopathy. The couple was known to be HSV-2 serodiscordant. A 2$\mathrm{mm}$ punch biopsy was performed under local anesthesia and the histologic examination revealed the presence of intraepidermal blistering with eosinophilic, sometimes swollen keratinocytes. Some keratinocytes presented intranuclear inclusions. Immunohistochemical identification revealed the presence of HSV-2 antigens (Fig. 3), but HSV-1 and VZV antigens were not detected. An initial treatment with topical antibiotics did not bring any relief. An oral treatment with aciclovir ( 2 x $500 \mathrm{mg} / \mathrm{d}, 7$ days) was initiated. Complete healing without scarring occurred after 6 days. Since, she never experienced a recurrence of $\mathrm{HSV}-2$ infection at this site.

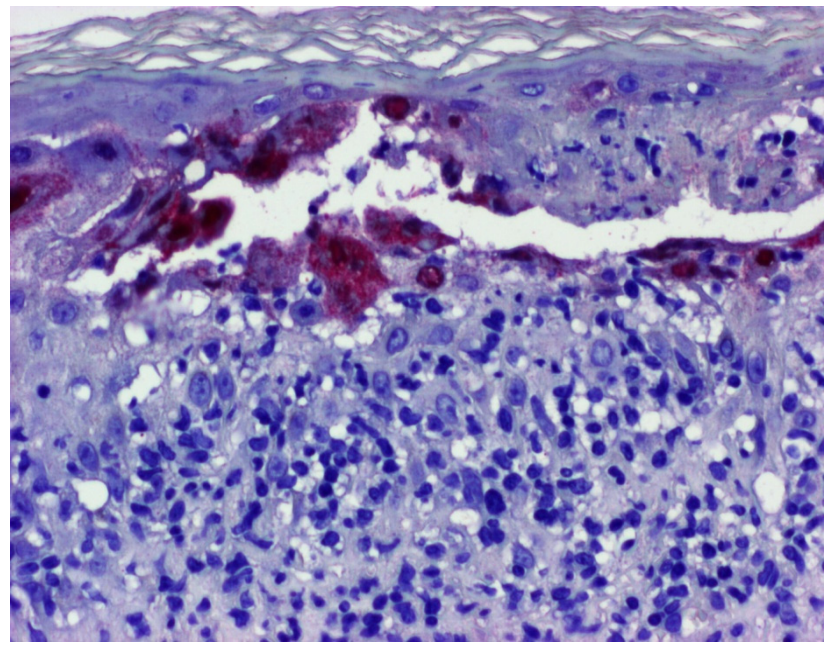

Fig. (3). HSV-1 positive immunostaining in epidermal keratinocytes (Skin biopsy, Red signal, 100x).

\section{DISCUSSION}

\section{Incidence}

HSV infection of the nipple and/or areola is very rare and has an estimated frequency of about $2 \%$ of all extragenital HSV lesions [8]. However, as the diagnosis is far from easy, it is probable that this entity is underdiagnosed. Up to date, only female patients have been reported in the literature [912]. All the patients were adults (19-48 years) and sexually active. All the publications reports single episodes and recurrent infections of the nipple were never mentioned.

\section{Viral Type}

The majority of infections are related to HSV-1 [11], whereas HSV-2 is more exceptional. However, viral identification is often not performed.

\section{Clinical Manifestations}

The dermatologic manifestations include small crops of blisters on an erythematous and slightly swollen base. Erosions, excoriations and ulcerations are often observed. Either the nipple is affected alone, but frequently the areola and periareolar area are also involved. Usually, these infections are unilateral $[11,13]$, but bilateral infections have been reported [our case, 14-16]. Infections are usually restricted to the nipple and areola [8] although cutaneous dissemination may occur [10]. Some infections are accompanied by a locoregional lymphadenopathy [13] whereas others are not. The healing time is about 7 to 10 days and does not differ from other anatomical sites. No scarring has been reported after HSV infection of the nipple. A very characteristic feature is moderate to severe pain, probably related to the high degree of nerve supply of the nipple and the neurotropic character of the virus [17].

\section{Risk Factors}

No particular risk factors exist besides atopic dermatitis [12] and local trauma.

\section{Complications}

HSV mastitis is a rare but feared complication $[11,13]$. The breast is swollen and indurated with a local painful lymphadenopthy. Another complication is the risk of infecting a newborn during breastfeeding [18]. Disseminated neonatal herpes infection can originate from HSV infection of the nipple of the mother [19]. Hence, breastfeeding is absolutely contraindicated in case of breast lesions [20,21].

\section{Transmission}

HSV infection of the nipple can be the result of a reactivation of a previous local infection or via a new transmission.

At least three modes of transmission may explain HSV infection of the nipple. Transmission can occur from infant to mother, as demonstrated by the acquisition of nipple herpes, originating from a primary gingivostomatitis in a baby $[14,15,22]$. In the non-lactating woman, contamination may occur through oral sexual contact $[10$, $11,16,23]$, such as a partner with recurrent labial herpes. In this instance, HSV-1 is the usual culprit. The partner's hand to nipple contact is also possible [13]. Autoinoculation may 
also occur from a RHL or a recurrent genital HSV infection of the patient herself $[4,13]$.

Reactivation has been suspected of an ancient local HSV infection of the nipple by a bite on the nipple by a new male partner without RHL whereas the former partner had RHL [11].

\section{Diagnosis}

The clinical diagnosis is very difficult as the disease is rare and is not part of the usual differential diagnoses.

The Tzanck test or cytodiagnosis, combined with immunohistochemistry (IHC), is the preferential method to identify HSV 1 or 2 in a very rapid, sensitive and specific way $[6,9,13,24,25]$.

Sometimes a punch biopsy is performed, especially as mammary Paget's disease is suspected $[10,13]$. The cytology reveals a ground-glass appearance of the nuclei with multinucleated syncytial cells. Subsequenlty, either IHC [6] or in situ hybridization (ISH) [24] using DNA probes may be used to search for HSV antigens or DNA.

PCR is another highly sensitive and specific method to identify HSV in clinical specimens [10,11].

Mammography reveals dense fibroglandular tissue with increased density of the affected breast. Skin thickening may be present. Ultrasonography shows areas of diffuse skin thickening [13]. However, mammography and ultrasonography are not diagnostic in the case of herpes of the nipple.

\section{Differential Diagnosis}

Herpes zoster restricted to the nipple is a difficult clinical differential diagnosis, in particular as both entities are linked to pain [25]. However, extension beyond the nipple and a dermatomal distribution are favoring herpes zoster. Furthermore, bacterial infection, dermatomycosis, atopic dermatitis, Darier's disease, periareolar abscess [26] and allergic contact eczema have to be eliminated. Erosive adenomatosis and mammary Paget's disease have also to be ruled out, especially in the elderly patient.

\section{Treatment}

As these infections are uncommon, the treatment recommendations are expert based but not evidence based. Oral aciclovir was initiated at $200 \mathrm{mg} 5 \mathrm{x} / \mathrm{d}$, for 5 to 7 days in the majority of the patients $[10,12,13]$. All patients healed after 7 to 10 days and no residual scarring was ever mentioned in the literature. Newer thymidine kinase dependant antivirals such as famciclovir and valaciclovir may also be considered as treatment alternatives. Topical disinfection is recommended.

\section{CONCLUSION}

HSV infection of the nipple and the periareolar area are uncommon entities that may easily be misdiagnosed. Severe pain combined with an unilateral or bilateral acute erosive dermatosis should suggest the diagnosis. Sexual contact, autoinoculation and breastfeeding are recognized risk factors. Aciclovir, famciclovir and valaciclovir are the antiviral drugs of choice.

\section{ACKNOWLEDGEMENT}

Declared none.

\section{CONFLICT OF INTEREST}

The authors confirm that this article content has no conflict of interest.

\section{REFERENCES}

[1] Castronovo C, Lebas E, Nikkels-Tassoudji N, Nikkels AF. Viral infections of the pubis. Int J STD AIDS 2012; 23: 48-50.

[2] Nikkels AF, Pièrard GE. Treatment of mucocutaneous presentations of herpes simplex virus infections. Am J Clin Dermatol 2002; 3: 475-87.

[3] Nahmias AJ, Roizman B. Infection with herpes simplex viruses 1 and 2. N Engl J Med 1973; 2897: 19-25.

[4] Whitley RJ, Nahmias AJ, Visintine AM, Fleming CL, Alford CA. The natural history of herpes simplex virus infection of mother and newborn. Pediatrics 1980; 66: 489-94.

[5] Tyring SK, Carlton SS, Evans T. Herpes. Atypical clinical manifestations. Dermatol Clin 1998; 16: 783-8.

[6] Nikkels AF, Debrus S, Sadzot-Delvaux C, et al. Comparative immunohistochemical study of herpes simplex and varicella-zoster infections. Virchows Arch A Pathol Anat Histopathol 1993; 422: 121-6.

[7] Nikkels AF, Piérard GE. The Tzanck smear: heading the right way! J Am Acad Dermatol 2009; 61: 152-3.

[8] Corey L, Adams HG, Brown ZA, Holmes KK. Genital herpes simplex virus infections: clinical manifestations, course, and complications. Ann Intern Med 1983; 98: 958-72.

[9] Mardi K, Gupta N, Sharma S, Gupta S. Cytodiagnosis of herpes simplex mastitis: Report of a rare case. J Cytol 2009; 26: 149-50.

[10] Watanabe D, Kuhara T, Ishida N, Takeo T, Tamada Y, Matsumoto Y. Disseminated mucocutaneous herpes simplex virus infection in an immunocompetent woman. Int J STD AIDS 2010; 21: 213-4.

[11] Brown H, Kneafsey P, Kureishi A. Herpes simplex mastitis: case report and review of the literature. Can J Infect Dis 1996; 7: 20912.

[12] Robinson GE, Underhill GS, Forster GE, Kennedy C, McLean K. Treatment with acyclovir of genital herpes simplex virus infection complicated by eczema herpeticum. Br J Vener Dis 1984; 60: 241 2.

[13] Soo MS, Ghate S. Herpes simplex virus mastitis: clinical and imaging findings. AJR Am J Roentgenol 2000; 174: 1087-8.

[14] Sealander JY, Kerr CP. Herpes simplex of the nipple: infant-tomother transmission. Am Fam Physician 1989; 39: 111-3.

[15] Quinn PT, Lofberg JV. Maternal herpetic breast infection: another hazard of neonatal herpes simplex. Med J Aust 1978; 2: 411-2.

[16] Dekio S, Kawasaki Y, Jidoi J. Herpes simplex on nipples inoculated from herpetic gingivostomatitis of a baby. Clin Exp Dermatol 1986; 2: 664-6.

[17] Amir L. Test your knowledge. Nipple pain in breastfeeding. Aust Fam Physician 2004; 33: 44-5.

[18] Dunkle LM, Schmidt RR, O’Connor DM. Neonatal herpes simplex infection possibly acquired via maternal breast milk. Pediatrics 1979; 63: 250-1.

[19] Sullivan-Bolyai JZ, Fife KH, Jacobs RF, Miller Z, Corey L. Disseminated neonatal herpes simplex virus type 1 from a maternal breast lesion. Pediatrics 1983; 71: 455-7.

[20] Henrot A. Transmission materno-foetale et indirecte de l'infection HSV, traitement et prévention. Ann Dermatol Venereol 2002; 129 : 533-49.

[21] Neifert MR. Returning to breast-feeding. Clin Obstet Gynecol 1980; 23: 1061-72.

[22] Gupta S, Malhotra AK, Dash SS. Child to mother transmission of herpes simplex virus-1 infection at an unusual site. J Eur Acad Dermatol Venereol 2008; 22: 878-9.

[23] Yoshida M. Herpetic pharyngitis with mammary and genital herpes due to sexual contact. Acta Derm Venereol 1999; 79: 250.

[24] Kobayashi TK, Okamoto H, Yakushiji M. Cytologic detection of herpes simplex virus DNA in nipple discharge by in situ hybridization: report of two cases. Diagn Cytopathol 1993; 9: 2969 . 
[25] Watanabe D, Kuhara T, Ishida N, Takama H, Tamada Y, Matsumoto Y. Herpes zoster of the nipple: rapid DNA-based diagnosis by the loop-mediated isothermal amplification method. Int J STD AIDS 2010; 21: 66-7.
[26] Higgins SP, Stedman YF, Bundred NJ, Woolley PD, Chandiok P, Chandler P. Periareolar breast abscess due to Pseudomonas aeruginosa in an HIV antibody positive male. Genitourin Med 1994; 70: 147-8.

(C) El Hayderi et al.; Licensee Bentham Open.

This is an open access article licensed under the terms of the Creative Commons Attribution Non-Commercial License (http: //creativecommons.org/licenses/by$\mathrm{nc} / 3.0 /$ ) which permits unrestricted, non-commercial use, distribution and reproduction in any medium, provided the work is properly cited. 